\title{
Iconicity of cohesion in Persian causative constructions ${ }^{*}$
}

\author{
Mohammad Ali Salmani Nodoushan, Gholamreza Mohiyedin Ghomshei (Tehran)
}

\begin{abstract}
This paper tries to show that Persian causative constructions are not only iconic in nature but also employ iconicity of cohesion in their syntactic structures productively. It starts with a description of iconicity and specifically focuses on the notion of conceptual distance as discussed by Haiman (1983). It then briefly reviews the formal typology of causative constructions (i. e., lexical, morphological, and periphrastic) and summarizes the ideas proposed by Comrie (1989), Dixon (2000), Shibatani (1976), and Talmy (2003) to come up with a list of, and a table for, the semantic properties of causative constructions (i. e., directness, coercion, control, manipulation, separability, and clause structure). The paper then presents tangible evidence and examples from Persian to claim that the linguistic distance observed between $\left[\mathrm{V}_{\text {cause }}\right]$ and $\left[\mathrm{V}_{\text {effect }}\right]$ in different types of Persian causative constructions mirrors the conceptual distance between them, and concludes that the iconic nature of causative constructions in Persian can be explained on the basis of the principle of iconicity of cohesion. It lends support to the universality of the principles of functional-cognitive linguistics and shows that iconicity theory still has a high potential for explaining form-meaning relations in different syntactic structures.
\end{abstract}

\section{$1 \quad$ Introduction}

This paper, with its focus on iconicity, is in support of functional-cognitive linguistics. In the last few decades, research on semiotics and functional-cognitive linguistics has witnessed an upsurge of interest in the study of the concept of iconicity. Iconicity has its roots in universal markedness theories which fall within the class of naturalness theories of language. Naturalness theories themselves fall into three categories: (a) universal markedness theories, (b) theories of typological adequacy, and (c) theories of language-specific system adequacy (cf. Dressler 1995). It has been argued within naturalness theories that they are for the most part based on the concept of universal preferences which are, as Dressler (ibd.: 23) argues, "parameterized, in so far as they either are directly expressed on universal, semiotically based parameters or as they follow from them" with iconicity being "the most natural and most popular parameter".

To further support the concept of iconicity, this paper reports on an evaluation of Persian causative constructions from the perspective of iconicity of cohesion (i. e., the conceptual distance

\footnotetext{
* This paper is based on the second author's unpublished $\mathrm{PhD}$ dissertation, Allameh Tabatabaii University, Tehran, Iran (2012). We would like to thank the anonymous reviewers for their thoughtful comments. We are aware that relevant works on the topic by some Iranian authors exist. However, in our opinion, there are certain good reasons why we do not wish to cite them.

We would like to thank the revered anonymous reviewers whose comments made it possible for us to add professionalism to the content of this paper. Special thanks also go to Professor Elke Hentschel for giving us the opportunity to get this work published in Linguistik online. We are also greatly indebted to Ms Nadine Kammermann, the layout editor of Linguistik online, without whose excellent and professional work this paper would never enjoy its current quality. To all many thanks again for your care, help, and support.
} 
principle). It strives to show that the relationships between meaning and form in different Persian causative constructions are iconic rather than arbitrary, and that these relationships can be adequately explained in the light of the conceptual distance principle.

\section{Iconicity}

The term iconicity has its roots in Charles Sanders Peirce's theory of semiosis (cf., Bains 2006; Hoffmeyer 1996), and is derived from the word icon, one of the three basic kinds of signs along with index and symbol (cf., De Cuypere/Willems 2008).

This particular trichotomy of signs is based on the relation between the representamen, viz. the "sign vehicle", and the object referred to. Basically, icons refer to their object based on similarity, indexes based on an existing or a contiguity relationship and symbols on conventionality. Additionally, three types of iconic signs (also called hypo-icons) are distinguished by Peirce. "Images represent their referent by means of simple qualities [...] Diagrams represent their object based on relational similarities [...] Finally, metaphors represent their object by referring to a parallelism between the object of the sign and another object." (De Cuypere/Willems 2008: 3)

As such, iconicity can be defined as the conceived similarity which is claimed to exist between the form of a sign and its meaning (cf., Haiman 1980; Newmeyer 1992). It stands at odds with arbitrariness which claims that the form-meaning relationship is conventional rather than being natural (cf., Frishberg 1975). In a discussion of the origins of iconicity, Croft (2003: 102) argues that the "intuition behind iconicity is that the structure of language reflects in some way the structure of experience." It is therefore a broad concept and belongs in different fields of inquiry including semiotics, functional-cognitive linguistics, philosophy, literature, and so on.

Although most of the sources found in the literature claim that iconicity theory is a product of the past three decades, it is not a new concept. Perhaps the earliest arguments about iconicity can be traced back to Plato's Cratylus, a dialogue in which he compares the original creation of a lexical item to the work of an artist; in much the same way as an artist simulates natural entities to create an artistic masterpiece, the creator of words uses natural linguistic elements to create words that iconically express the essence of their subjects (cf., Sedley 2003). Perhaps the first modern linguist to oppose the concept of iconicity in linguistics is Ferdinand de Saussure (1916) who argued in favor of arbitrariness and claimed, in Lyons' terms, that "the association of a particular sound or letter with a particular expression-element is a matter of arbitrary convention" (Lyons 1968: 63); by way of contrast, Sapir can be considered the first modern linguist who supported iconicity by considering the process of reduplication as a "process [...] generally employed, with self-evident symbolism, to indicate such concepts as distribution, plurality, repetition, customary activity, increase of size, added intensity, continuance" (ibd. 1921: 79).

Benveniste (1939) and Jakobson (1971), too, were among the first linguists who supported iconicity. Jakobson's position was rather radical in that he attacked what he called Saussure's "dogma" of linguistic arbitrariness in his pioneering article "Quest for the essence of language" thereby paving the way for the study of what has come to be known as linguistic iconicity in the modern sense of the word (cf., De Cuypere/Willems 2008). In recent years, iconicity and naturalness have been the focus of attention for several linguists who work in domains other than the functional-cognitivist camp (cf., Aissen 2003; Bresnan/Aissen 2002; Newmeyer 1992) although other linguists have attempted to discard iconicity from linguistics (Bouissac 2005; Haspelmath 2008a, 2008b). There are even well-known linguists who use the term iconic in a loose sense to describe different kinds of linguistic phenomena. For instance, Rooryck (1992), in an eloquent discussion of raising and control, argues that a given verb class has the potential of exerting "an 'iconic' influence on another semantically related verbs class" (ibd.: 10).

Ever since its introduction, language philosophers and linguists have tried to come up with orderly and organized taxonomies of iconicity. On the morpho-syntactic plane, which is the 
principle axis of this paper, most of the attempts at classifying iconic elements have culminated in the introduction of three major principles of morpho-syntactic iconicity: (a) the principle of adjacency, (b) the principle of sequential order, and (c) the iconic principle of cohesion (cf., Moravcsik 1978; Wilcox 2004).

The adjacency principle is based on the operandum-operator dichotomy. Each syntactic structure is claimed to have an axial indispensable element (or head) and one or more subordinate elements - modifiers (or operators) - which are normally expected to be as close to their heads as possible (cf., De Cuypere/Willems 2008). In cases where an operandum has more than one operator, the distance of the operators from the operandum (i. e., their order) is controlled by their degree of relevance to the operandum; the most relevant operator is put closest to the operandum, and the least relevant is placed far from it. For instance, in a noun phrase which includes several adjectives, the order of adjectives is the mirror reflection of the order of the relevance of the adjectives to the noun (cf., Van Langendonck 1995).

On the other hand, the sequential order principle holds that "the order of clauses in coherent discourse will tend to correspond to the temporal order of the occurrence of the depicted events" (Givón 1990 cited in De Cuypere/Willems 2008: 5). This can perhaps be best understood when one compares they married and had a baby with they had a baby and married. Finally, the principle of cohesion, which is also known as the proximity principle of iconicity, has to do with the notion of conceptual distance. In simple terms, this principle argues that the formal distance observed between linguistic signs within a sentence or a text is controlled and motivated by the conceptual distance which is denoted in the state of affairs (cf., ibd.). The cohesion/proximity principle, the reverse of which is called alienation, holds that linguistic signs are conceptually close if they (a) are perceived as inseparable, (b) share several/many semantic properties, or (c) affect each other (cf., Haiman 1983, 1992). Causativity is perhaps one of the areas in which the cohesion principle of morpho-syntactic iconicity can be fruitfully studied.

\section{Causativity}

According to De Cuypere (2008: 146), causativity refers to the lexical or grammatical expression of the causal state of events in the sense that somebody or something causes something, some event, or some state. In other words, causativity encompasses a rich repertoire of morphological, lexical or syntactic forms which, when used, make someone, something, or some event function as the cause, stimulus, or motivation for someone else or some other thing or event to act, accept a state, or remain in a state. In a discussion of causativity, Velázquez-Castillo (2001: 508) assumes that any causative situation necessarily consists of (a) a causing event and (b) an effected event which must stand in the following relations to each other:

i. a temporal sequence such that the causal event precedes the effected event,

ii. a semantic entailment relation between the causing event and the effected event in that the truth of the effected event holds whenever that of the causing event holds,

iii. the causing event adds a layer of energy to the effected event.

Velázquez-Castillo (2001: 508) also notices that the first of these relations is "present in different degrees in causative constructions" and is responsible for the creation of "a spectrum of possibilities in relation to event integration" and also argues that the same is true for the third of these relations which results "in a range of possibilities with respect to forcefulness" (cf., Comrie 1981; Dixon 2000; Shibatani 2001; Song 1996). In addition to the causing and caused events, direct causativity requires a causer to play the agent/stimulus role, and a causee to play the role of the patient/experiencer (Shibatani 1976). Take the following example from Persian: 
$\begin{array}{lllllll}\text { 1) Ali } & \text { pesar } & \text { raa } & \text { vaadaar kard } & \text { ke } & \text { takaalifash } & \text { raa anjaam dahad }{ }^{1} \\ \text { Ali boy } & \text { the }^{2} & \text { forced } & \text { that homework-his to do }\end{array}$

'Ali forced the boy to do his homework.'

where

a) causing event $=$ forcing to do homework

b) caused event $=$ homework being done

c) causer $=$ he

d) causee $=$ the boy

e) causal relation between (a) and (b) in that (b) would not occur if (a) did not happen.

f) temporal relation between (a) and (b) in that (a) is prior (Event1 or E1) to (b) which is posterior (Event2 or E2)

\subsection{Typology of causative constructions}

Causative constructions have been classified into two major groups based on their formal attributes (cf., Jackendoff 1991; Shibatani 1976; Spencer 1991): (1) periphrastic (sometimes referred to as analytic or syntactic), and (2) lexical and morphological. The main difference between these two classes of causative constructions is that in the periphrastic class the causing event and the caused event have their own independent verbs; they may even sometimes be stated in different predicates (or clauses). In the lexical/morphological causative construction, however, both the causing and the caused events are stated in the same clause. It should be noted that morphological and lexical causativity are sometimes differentiated in that the former employs affixation whereas the latter employs causative vs. non-causative pairs of lexical items (or even 'fusion'); some verbs are both transitive and intransitive, and their transitivity and intransitivity are so seamlessly fused together that they take on the same linguistic form for both cases; hence, fusion.

Using the material encoding the causing and the caused events, Comrie (1981) classifies causatives into three main classes: (1) lexical, (2) morphological, and (3) analytic. For Comrie, a lexical causative is one in which both events (i. e., causing and caused) are expressed in a single lexical item (e. g., the English word break). A morphological causative, on the other hand, is one in which the two events are encoded in a single verbal complex with marking as the elements that show the status of affected arguments. Finally, an analytic causative is one in which each of the events is encoded in separate clause (ibd.).

Song (1996) culls a rich database which includes examples from six hundred different languages to suggest a classification of causative constructions with the three classes of (1) COMPACT, (2) AND, and (3) PURP. To this end, he suggests a certain kind of terminology which consists of the following items:

\footnotetext{
1 Please see Appendix A for a guide to phonetic symbols used in this paper.

2 Traditional grammars of Persian consider $r a$ an object marker; however, syntactic argumentation by Professor Mohammad Dabir Moghaddam (Class notes, PhD course in Language Science, University of Tehran, Spring 1998) have revealed that $r a$ is indeed a determiner similar to the in English which distinguishes between definite and generic nouns albeit in the object position.

Compare:

Hasan naan xord. ('Hasan ate bread.')

Hasan naan raa xord. ('Hasan ate the bread.')
} 
- $\left[\mathrm{S}_{\text {cause }}\right]$ : This refers to the clause which denotes a causing event.

- $\left[\mathrm{S}_{\mathrm{effect}}\right]$ : This refers to the clause which denotes the caused event.

- $\quad\left[\mathrm{V}_{\text {cause }}\right]$ : This stands for the verbal elements of [ $\left.\mathrm{S}_{\text {cause }}\right]$

- $\quad\left[V_{\text {effect }}\right]$ : This signifies the verbal elements of $\left[\mathrm{S}_{\text {effect }}\right]$

In this taxonomy, the range of lexical and morphological causatives are merged and called COMPACT in which [ $\left.\mathrm{V}_{\text {cause }}\right]$ may even be a bound morpheme, zero-derivation, or a suppletion. The COMPACT can also be a free morpheme in which both [ $\left.\mathrm{V}_{\text {cause }}\right]$ and $\left[\mathrm{V}_{\text {effect }}\right]$ form a single grammatical unit (Song 1996). The AND causative is periphrastic in nature in that $\left[\mathrm{S}_{\text {cause }}\right]$ and [Seffect] appear in different clauses. The PURP causative is a specific case in which the speaker encodes the [ $\left.\mathrm{V}_{\text {cause }}\right]$ and causer intentionality but deliberately or otherwise fails to encode the $\left[\mathrm{V}_{\text {effect }}\right]$ as if the speaker does not know if the $\left[\mathrm{V}_{\text {effect }}\right]$ was felicitously effected.

In typology of causative constructions, Dixon (2000) embarks on a detailed elaboration of the syntax and semantics of causativity and identifies nine classes of causatives based on the roles and characteristics of lexical verbs, causers, and causees. The first two classes have to do with the kinds of lexical verbs employed in causative constructions and include (1) stative vs. active and (2) intransitive vs. transitive vs. ditransitive types. The next three classes have to do with the roles and qualities of the causee and include (3) having vs. lacking control over the caused microevent, (4) acting willingly vs. unwillingly, and (5) being partially affected vs. completely affected. Finally, the last four classes relate to the intentions, involvement and willingness of the causer and include (6) acting directly vs. indirectly, (7) acting accidentally vs. intentionally, (8) acting naturally vs. with effort depending on the amount of effort used for the initiation of the caused microevent, and (9) being personally involved vs. not involved in the caused microevent (cf., ibd.). Dixon applies this typology to a corpus of causative constructions which includes data from 25 languages and concludes that the 9th parameter (i. e., being personally involved vs. not involved in the caused microevent) is the least productive.

Still another typology (which is mainly lexical in nature) is proposed by Talmy (2003). This typology carries the label lexicalization patterns and is in fact a classification for semantic causative types. Like Dixon's taxonomy, this taxonomy uses nine parameters which are: (1) autonomous events (non-causative), (2) resulting-event causation, (3) causing-event causation, (4) instrument causation, (5) author causation (unintended), (6) agent causation (intended), (7) undergoer situation (non-causative), (8) self-agentive causation, and (9) caused agency (inductive causation) (cf., ibd.).

\subsection{Semantic properties of causatives}

The typologies described above employ semantic differences (e. g., Dixon 2000) and differences in logic (e. g., Talmy 2003) as their classification criteria. A review of the literature on causative constructions also shows that in many of the classifications presented to this date, binary criteria have been employed the most important of which are: (a) coercive vs. noncoercive, (b) directive vs. manipulative, (c) direct vs. indirect, and (c) ballistic vs. controlled (Shibatani 1975). Such binary classifications are sensitive to, and based on, semantic contexts. The distinction between coercive and noncoercive causatives is based on the amount of force - often physical - that is exerted by the causer on the causee. Take the following example where (a) is coercive and (b) noncoercive.

$\begin{array}{lllll}\text { 2) a) parastaar } & \text { daaru } & \text { raa be } & \text { budak } & \text { xoraanid } \\ \text { nurse } & \text { medicine } & \text { the } & \text { to } & \text { child } \\ \text { forced to eat }\end{array}$ 'The nurse made the childe take the medicine.' 
$\begin{array}{llllll}\text { b) parastaar baa?es shod } & \begin{array}{l}\text { ke kudak daaru } \\ \text { nurse }\end{array} \text { made } & \text { that child medicine the eat }\end{array}$

'The nurse caused the child to take the medicine.

By way of comparison, directive causation indicates that the animate causee is volitionally submissive to the causing event (e. g., a request). In manipulative causation, on the other hand, inanimate causees that are not able to volitionally resist the causing event are manipulated by the causer (e. g., a car getting fixed by a mechanic) (Shibatani 1975). 3(a) is an example of directive causatives and 3(b) an example of manipulative causatives. $\begin{array}{lllllll}\text { 3) a) raanandeh az mekaanik xaast mashinash raa ta?mir konad. } \\ \text { driver } & \text { of mechanic wanted car-his the fixed do }\end{array}$ 'The driver had the mechanic fix his car.'

b) mekaanik maashin raa ta?mir kard mechanic car the fix did 'The mechanic fixed the care.'

Along the same lines, direct causatives draw on a straightforward way of causing the effect event whereas indirect causatives use secondary or intermediary means of achieving this goal (Shibatani 1975). In direct causatives, the causer directly influences the causee so that the effect event will happen while in indirect causatives a third element mediates between the causer and the causee. It is on this ground that direct versus indirect causatives have also been called contact vs. distant or immediate vs. mediated causatives. As Shibatani and Pardeshi (2001: 122) put it, "In the case of direct causation, the causer's action carries over to the caused event, whereas in indirect causation the caused event enjoys an autonomous status free of the causer's intervention." In example 4 below, (a) is an instance of direct causatives and (b) an indirect one.

4) a) sarPaashpaz Paashpaz raa majbur kard saalaad raa mohayyaa
chef
cook pare

'The chef made the cook prepare the salad.'

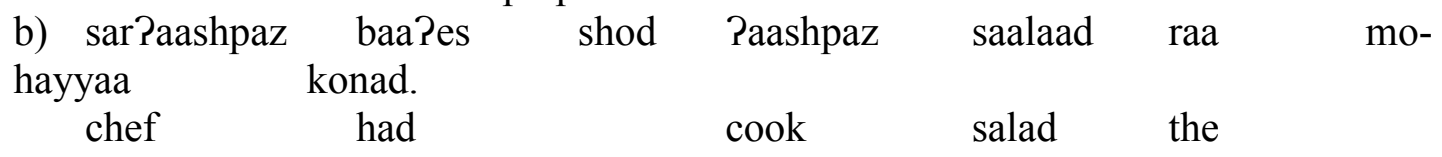

prepare

'The chef had the cook prepare the salad.'

Shibatani and Pardeshi (2001) also argue that in direct causatives both the causing event and the caused event happen simultaneously and in the same locative setting while in indirect causatives the caused event may follow from the causing event with a time interval between the two, and they may happen in different locative settings. In other words, the "difference between the two is reflected in the differences of the spatiotemporal profiles (captured in word-order and tense) associated with the causing and the caused event" (ibd.: 122). Shibatani and Pardeshi also redefine the direct-indirect dichotomy and suggest that there is a continuum of directness with direct causatives at one end and indirect causatives at the other. They notice that "an important intermediate category of causation bridges the direct and the indirect situation in such a way as to turn the entire directness dimension of the causative semantics into a continuum" to which they refer as "intermediate, sociative causatives" (ibd.: 122).

In ballistic causation, the causer is just the initiator of the causing event and has no further role in the process. In controlled causatives, on the other hand, the causer is present throughout the 
process and has control over it. As such, the causer in ballistic causation just instigates or foments that process; in controlled causation, however, the causer accompanies causation from the start to the end; hence, 'instigating versus accompanying' causation (Bishop 1992). In example 5 below, (a) is ballistic and (b) is controlled.

5) a) zelzeleh earthquake baa?es shod caused

b) banana mason saaxtemaan 'The mason built the building in one year.' sunaami ye tsunami of tsunami.' raa dar the in
Pazimi huge

yek one
Pijaad shavad. beformed.

saal saaxt.

year built

\section{$4 \quad$ Iconicity in causatives}

The study of form-meaning relations in causative constructions of the different languages of the world is not a new subject. Comrie $(1981,1985)$ notices that the apparent difference in the semantics and meaning of direct versus indirect causations mirrors a kind of structural/formal difference in the two causative types. He even goes on to claim that the relations between form and meaning in causative constructions are more or less the same in the different languages of the world. Drawing on a formal typology of causatives (i. e., lexical vs. morphological vs. periphrastic), he further suggests that "these three types form a continuum, and each type, furthermore, consists of a continuum of its own, rendering the entire formal dimension into a single continuum" (Shibatani/Pardeshi 2001: 85). He also suggests that the degrees of form-meaning relationship (lexical vs. morphological vs. periphrastic) are not the same; lexical causatives stand at one end of the form-meaning continuum to show the highest degree of form-meaning relationship, morphological causatives occupy the middle-of-the-continuum position thereby indicating a medium degree of form-meaning relationship, and periphrastic causatives stand at the opposite end to show the lowest degree of form-meaning relationship (cf., Givón 1980).

Along the same lines, Dixon (2000) uses a compactness criterion and suggests a continuum along which he classifies different causative constructions from the formal typology of lexical vs. morphological vs. periphrastic causatives. In Dixon's terms, lexical causatives manifest that highest degree of compactness in that the causing event and the caused event are so close that they can be considered inseparable. Dixon's compactness continuum sorts the formal aspects of causativity from less compact (i. e., periphrastic constructions) to most compact (i. e., lexical causatives). Figure 1 is the schematic representation of Dixon's scale of compactness.

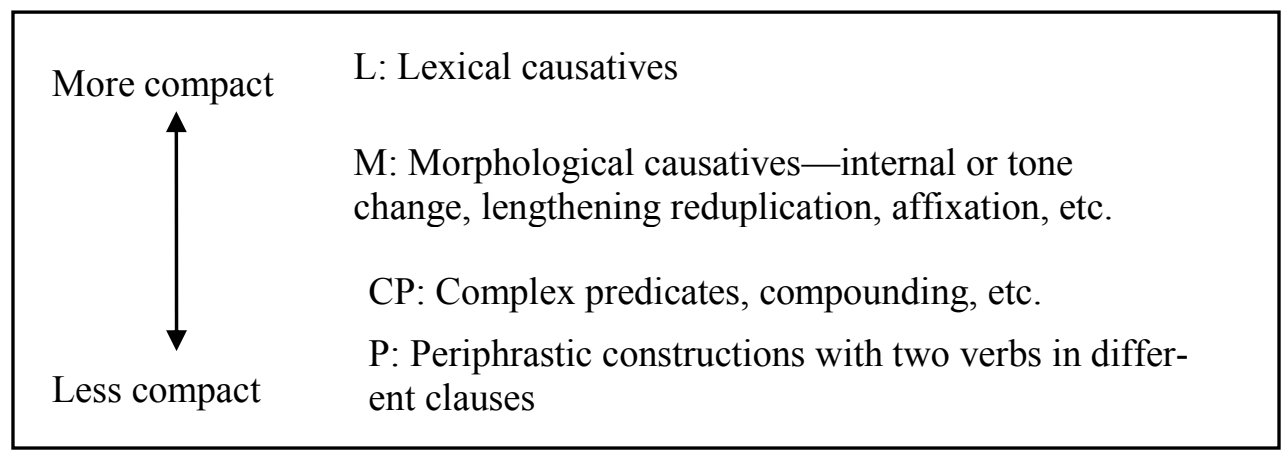

Fig. 1: Dixon's scale of compactness (cf., Dixon 2000: 74).

These discussions are based on a claim that is on a par with the iconicity principle in that the claim basically assumes a correlation between the level or degree of formal compactness of the material that encodes the causative microevent and the perceived directness of the relationship that exists between [ $\left.\mathrm{V}_{\text {cause }}\right]$ and $\left[\mathrm{V}_{\text {effect }}\right]$ (cf., Huang/Su 2005). In other words, shorter more compact forms (e. g., lexical causatives) encode more direct causation, and longer less compact 
forms (e. g., periphrastic causatives) encode more indirect causation. This implies that directness/indirectness is not dichotomous but is rather continuous. It is on this ground that Shibatani and Pardeshi (2001: 109) propose a formal causative continuum. Figure 2 displays this continuum.

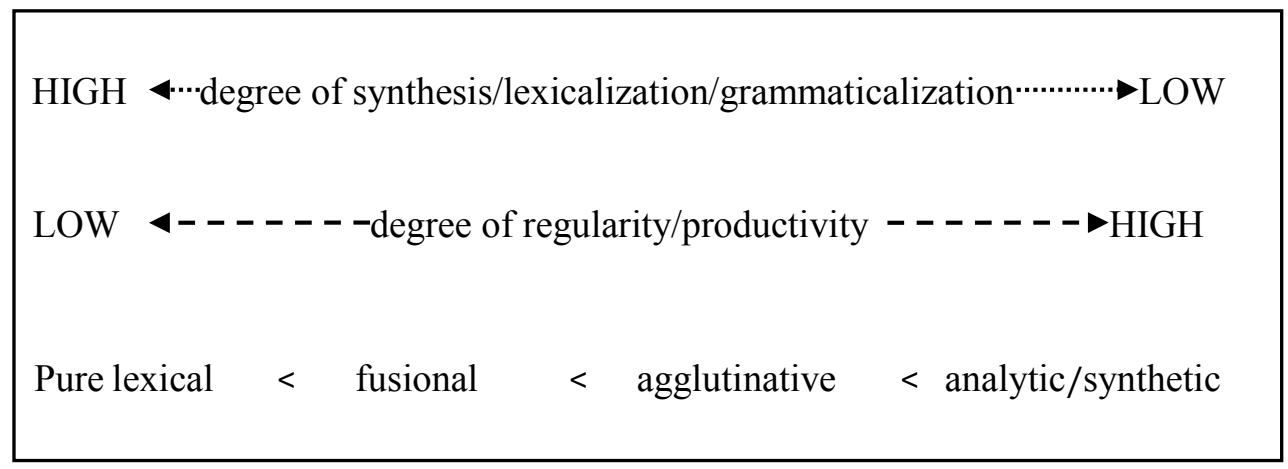

Fig. 2: Formal causative continuum (cf. Shibatani/Pardeshi 2001: 109).

It was stated in section 2 (above) that the principle of cohesion in iconicity has to do with the notion of conceptual distance. It was also stated that the principle simply claims that the formal distance observed between linguistic signs within a sentence or a text is controlled and motivated by the conceptual distance which is denoted in the state of affairs (cf., De Cuypere/Willems 2008). It was further argued that linguistic signs are conceptually close if they are perceived as inseparable, share several/many semantic properties, or affect each other (Haiman 1983, 1992); moreover, it was claimed that causativity is perhaps one of the areas in which the cohesion principle of morpho-syntactic iconicity can be fruitfully studied. In fact, Dixon's compactness scale bears witness to the iconic nature of causative constructions.

To recapitulate, iconicity of cohesion is defined as follows: "Meanings that belong together more closely are expressed by more cohesive forms" (Haspelmath, 2008a: 13). Haiman (1983: 72) provides a detailed discussion of iconicity of cohesion under the rubric of "iconic expression of conceptual distance" and argues that "The linguistic distance between expressions corresponds to the conceptual distance between them". This quotation from Haiman has two components: (a) linguistic distance, and (b) conceptual distance. Linguistic formal distance can be shown in terms of diminishing linguistic distance or increasing cohesion as indicated in Figure 3.

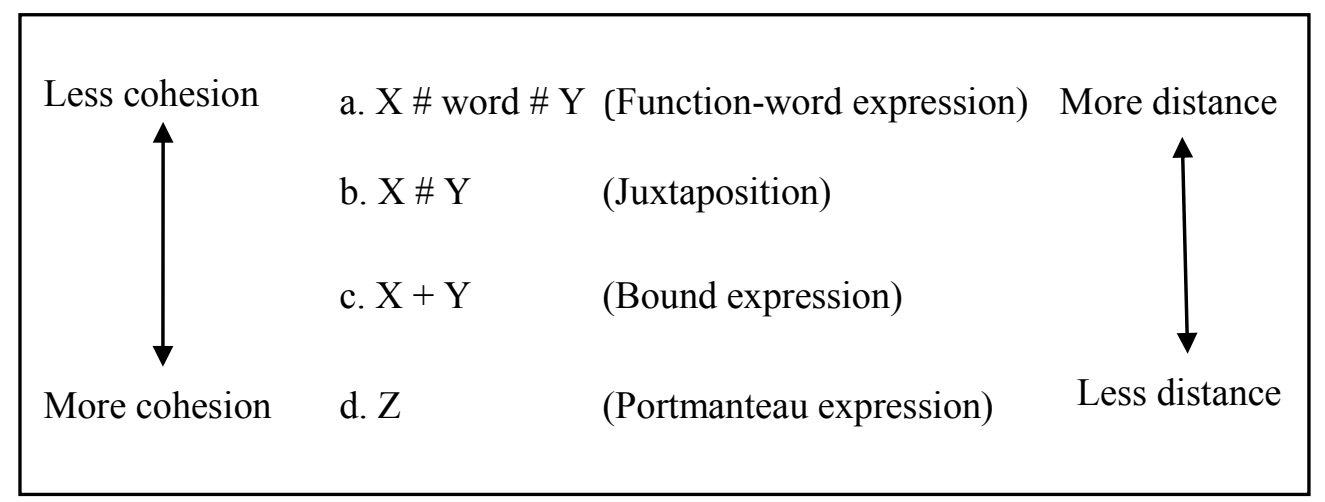

Fig. 3: Haiman's iconic expression of conceptual distance (cf., Haiman 1983).

Haspelmath argues that cohesion should be preferred to distance because "(b) and (c) do not literally differ in distance, and distance is not really applicable to (d)" (id. 2008a: 13). Haiman also used the term conceptual distance which needs clarification here. In order to afford an operational definition of conceptual distance, Haiman (1983) argues that two concepts can be considered as conceptually close (a) if they share semantic properties, (b) when one affects the other, or (c) when both are perceived as inseparable. It is perhaps on this basis that Haspelmath (2008a) argues that the most important cases cited as examples of iconicity of cohesion in the 
literature are (a) possessive constructions, (b) coordinating constructions, (c) complement clause constructions, and (d) causative constructions.

In connection to the iconicity of causative constructions, Haiman (1983) argues that causative constructions which show a greater degree of cohesion express direct causation (where cause and result belong together more closely); by the same token, causative constructions that show less cohesion express indirect causation (cf., Comrie 1989; Dixon 2000). In this connection, Lakoff and Johnson (1980) argue that the best example of iconicity of causative constructions can be found in the much-discussed English distinction between kill and cause to die.

\section{$5 \quad$ Iconicity in Persian causatives: The cohesion principle}

In this section, we shall provide examples from Persian to argue that the cohesion/proximity principle is the key factor in determining the directness/indirectness of Persian causative constructions.

\begin{tabular}{|c|c|c|c|c|c|c|}
\hline $\begin{array}{l}\text { 6) Pafsar } \\
\text { officer } \\
\text { causer }\end{array}$ & $\begin{array}{l}\text { baa?es shod } \\
\text { had } \\
{\left[\mathrm{V}_{\text {cause }}\right]}\end{array}$ & $\begin{array}{l}\text { zendaaniaan } \\
\text { prisoners } \\
\text { cause }\end{array}$ & $\begin{array}{l}\text { dor } \\
\text { around }\end{array}$ & $\begin{array}{l}\mathrm{e} \\
\text { of }\end{array}$ & $\begin{array}{l}\text { zamin } \\
\text { field }\end{array}$ & $\begin{array}{l}\text { bedavand. } \\
\text { run } \\
{\left[\mathrm{V}_{\text {effect }}\right]}\end{array}$ \\
\hline
\end{tabular}
'The officer had the prisoners run around the field.'

Example 6 complies with Haiman's "X \# word \# Y" scale of linguistic distance, and is perceived as an indirect type of causative construction by Persian native speakers. By way of contrast, Example 7 (below) complies with Haiman's "X+Y" scale of linguistic distance and carries more directness.

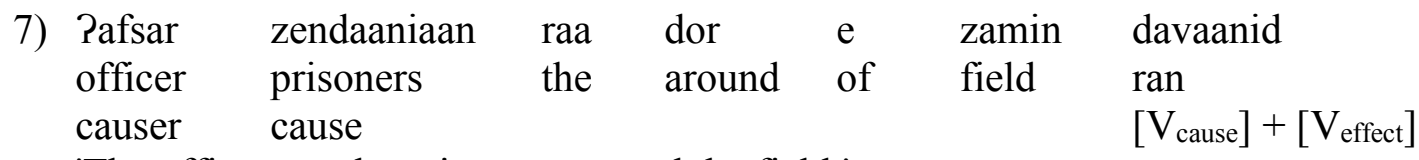
'The officer ran the prisoners around the field.'

In example 7, the Persian suffix -aanid has been added to the Persian verb root dav to create a morphological causative. It is also possible to find Haiman's "Z" scale in Persian causatives. Example 8 shows the linguistic distance expressed by the "Z" scale where two morphemes undergo fusion and change into a morphologically unanalyzable unit with the same surface form.

8) reza livaan raa shekast.
Reza mug the broke
causer cause
'Reza broke the mug.'

Examples 6 through 8 show that linguistic distance is part and parcel of different Persian causative construction. However, this does not show their iconic nature in and of itself unless we can show that the observed linguistic distances in different causative constructions in Persian follow from appropriate conceptual distances. To this end, we need to return to the conceptual criteria that Haiman (1983) suggested for measuring conceptual distance (i. e., that two concepts can be considered as conceptually close (a) if they share semantic properties, (b) when one affects the other, or (c) when both are perceived as inseparable) (cf., Comrie 1989; Dixon 2000; Shibatani 1975; Shibatani/Pardeshi 2001). It is, therefore, necessary to evaluate examples 6 through 8 in the light of these conceptual criteria. Table 1 lists the semantic properties of different Persian causative constructions. 


\begin{tabular}{|c|c|c|c|c|}
\hline & \multicolumn{3}{|c|}{ Formal Distance } \\
\hline & & 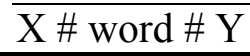 & $\mathrm{X}+\mathrm{Y}$ & $\mathrm{Z}$ \\
\hline \multirow[t]{2}{*}{$\overline{\text { Directness }}$} & Direct & - & + & + \\
\hline & Indirect & + & - & - \\
\hline \multirow[t]{2}{*}{ Coercion } & Coercive & \pm & + & + \\
\hline & Noncoercive & \pm & - & - \\
\hline \multirow[t]{2}{*}{ Control } & Ballistic & + & - & - \\
\hline & Controlled & - & + & + \\
\hline \multirow[t]{2}{*}{ Manipulation } & Manipulative & \pm & + & + \\
\hline & Directive & \pm & - & - \\
\hline \multirow[t]{2}{*}{ Separability } & Separable & + & + & - \\
\hline & Fusion & - & - & + \\
\hline \multirow[t]{2}{*}{ Clause Structure } & Mono-clausal & - & + & + \\
\hline & Bi-clausal & + & - & - \\
\hline
\end{tabular}

Tab. 1: Semantic Properties of Persian Causative Constructions.

When the formal and conceptual properties of example 6 are compared, it can be concluded that there is a direct relationship between the two. In other words, in example 6:

a) the formal distance between $\left[\mathrm{V}_{\text {cause }}\right]$ and $\left[\mathrm{V}_{\text {effect }}\right]$ as expressed by "X \# word \# $\mathrm{Y}$ " is large;

b) the conceptual distance as understood from the conceptual properties [+indirect, \pm coercive, +ballistic, +separable, +bi-clausal] is large;

c) there is correspondence between formal and conceptual distance;

d) therefore, the iconicity of this kind of causatives is supported.

As for example 7, the following premises can be postulated:

a) The formal distance between $\left[\mathrm{V}_{\text {cause }}\right]$ and $\left[\mathrm{V}_{\text {effect }}\right]$ as expressed by "X+Y" is not that large;

b) the conceptual distance as understood from the conceptual properties [+direct, + coercive, +controlled, +manipulative, +separable, +mono-clausal] is not that large either;

c) there is correspondence between formal and conceptual distance;

d) therefore, the iconicity of this kind of causatives is supported.

In relation to example 8 , the iconic nature of the causative construction can be established on the basis of these premises:

a) The formal distance between $\left[\mathrm{V}_{\text {cause }}\right]$ and $\left[\mathrm{V}_{\text {effect }}\right]$ as expressed by "Z" is zero;

b) the conceptual distance as understood from the conceptual properties [+direct, +coercive, +controlled, +Fusion, +mono-clausal] is zero;

c) there is correspondence between formal and conceptual distance;

d) therefore, the iconicity of this kind of causatives is supported.

\section{Conclusion}

Persian causative constructions fall into three formal classes based on the formal linguistic distance between their $\left[\mathrm{V}_{\text {cause }}\right]$ and $\left[\mathrm{V}_{\text {effect }}\right]$ : (1) X \# word \# Y, (2) X+Y, or (3) Z. It should be noted that the grammar of Persian does not allow the "X \# Y" type to occur in Persian causatives. Nevertheless, there are "marked" instances of this scale in spoken Persian, but native speakers 
know, based on their competence, that in those spoken forms there is an elliptical relative pronoun. Take example 9.

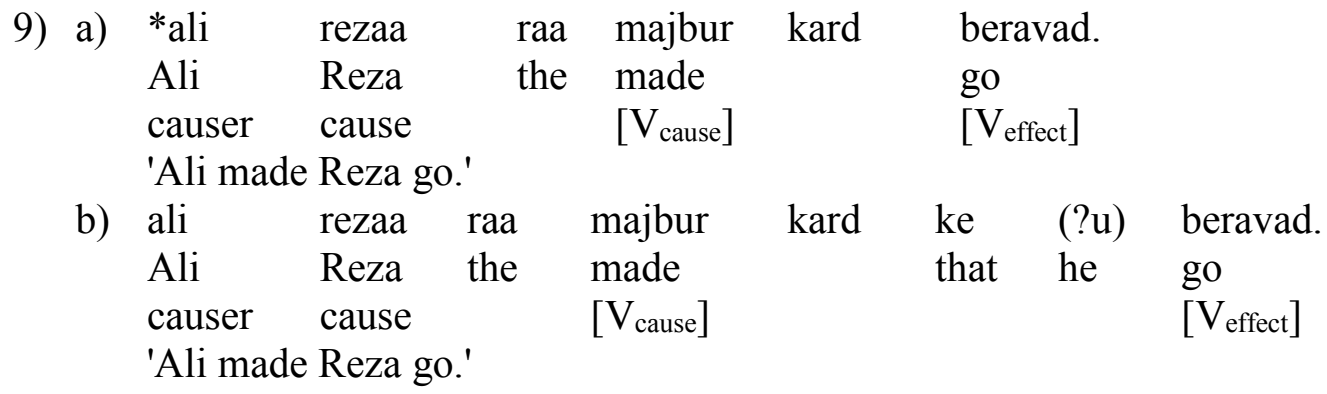

As such, some linguists consider 9(a) ungrammatical when it is used in writing, and marked when used in speech. This implies that juxtaposition is not a natural phenomenon in Persian, and does not occur in Persian causative constructions.

In sum, this paper tried to show that Persian causative constructions are iconic based on Haiman's conceptual distance principle; it can be concluded, based on the discussion presented in this paper that there is a positive correlation between the formal and conceptual properties of Persian causative constructions. It can also be concluded that iconicity of cohesion can adequately explain this correlation. The paper lends support to the universality of the principles of functional-cognitive linguistics and shows that iconicity theory still has a high potential for explaining form-meaning relations in different syntactic structures.

At the time of publication of this article, Mohammad Ali Salmani Nodoushan and Gholamreza Mohiyedin Ghomshei are affiliated with Iranian Institute for Encyclopedia Research, Tehran, Iran.

\section{References}

Aissen, Judith (2003): "Differential object marking. Iconicity vs. economy". Natural Language and Linguistic Theory 21: 435-483.

Bains, Paul (2006): The primacy of semiosis. An ontology of relations. Toronto: University of Toronto Press.

Benveniste, Émile (1939): "Nature du signe linguistique". Acta Linguistica 1/1: 23-29.

Bishop, Nancy (1992): "A typology of causatives, pragmatically speaking". In: Hwang, Shin J. J./Merrifield, William R. (eds.): Language in context. Essays for Robert E. Longacre. Summer Institute of linguistics: 295-304. (= Summer Institute of Linguistics and The University of Texas at Arlington Publications in Linguistics 107).

Bouissac, Paul (2005): "Iconicity or iconization? Probing the dynamic interface between language and perception". In: Maeder, Costantino/Fischer, Olga/Herlofsky, William J. (eds.): Outside-in-inside-out. Amsterdam, John Benjamins: 15-37.

Bresnan, Joan W./Aissen, Judith (2002): "Optimality and functionality. Objections and refutations". Natural Language and Linguistic Theory 21: 81-95.

Comrie, Bernard (1981): Language universals and linguistic typology. Syntax and morphology. Chicago: University of Chicago Press.

Comrie, Bernard (1985): "Causative verb formation and other verb-deriving morphology". In Shopen, Timothy (ed.): Language typology and syntactic description, Vol. III. Cambridge, Cambridge University Press: 309-348..

Comrie, Bernard (1989): Language universals and linguistic typology. $2^{\text {nd }}$ ed. Oxford: Blackwell.

Croft, William (2003): Typology and universals. $2^{\text {nd }}$ ed. Cambridge: Cambridge University Press. 
De Cuypere, Ludovic D. (2008): Limiting the iconic. From the metatheoretical foundations to the creative possibilities of iconicity in language. Amsterdam: John Benjamins.

De Cuypere, Ludovic D./Willems, Klaas (2008): "Introduction". In: De Cuypere, Ludovic D./Willems, Klaas (eds.): Naturalness and iconicity in language. Amsterdam, John Benjamins: $1-23$.

Dixon, Robert M. W. (2000): "A typology of causatives. Form, syntax and meaning". In: Dixon, Robert M./Aikhenvald, Alexandra Y. (eds.): Changing valency. Cambridge, Cambridge University Press: $30-83$.

Dressler, Wolfgang U. (1995): Interactions between iconicity and other semiotic parameters. In: Simone, Raffaele (ed.): Iconicity in language. Amsterdam, John Benjamins: 21-38.

Frishberg, Nancy (1975): "Arbitrariness and iconicity. Historical change in America". Language 51/3: 696-719.

Givón, Talmy (1980): "The binding hierarchy and the typology of complements". Studies in Language 4: 333-377.

Givón, Talmy (1990): Syntax. A functional-typological introduction. Amsterdam: John Benjamins.

Haiman, John (1980): "The iconicity of grammar. Isomorphism and motivation". Language 56: $515-540$.

Haiman, John (1983): "Iconic and economic motivation". Language 59: 781-819.

Haiman, John (1992): "Iconicity". In: Asher, Ron E. (ed.): International encyclopedia of linguistics. Oxford, Oxford University Press: 191-195.

Haspelmath, Martin (2008a): "Frequency vs. iconicity in explaining grammatical asymmetries". Cognitive Linguistics 19/1: 1-33.

Haspelmath, Martin (2008b): "Reply to Haiman and Croft". Cognitive Linguistics 19/1: 59-66.

Hoffmeyer, Jesper (1996): Signs of meaning in the universe. Bloomington: Indiana University Press.

Huang, Shuping/Su, Lily I. W. (2005): "Iconicity as evidenced in Saisiyat linguistic coding of causative events". Oceanic Linguistics 44/2: 341-356.

Jackendoff, Ray (1991): Semantic Structures. Cambridge, MA.: The MIT Press.

Jakobson, Roman (1971): "Quest for the essence of language". In: Jakobson, Roman (ed.): Selected writings II. The Hague, Mouton: 345-359.

Lakoff, George/Johnson, Mark (1980): Metaphors we live by. Chicago: University of Chicago Press.

Lyons, John (1968): Introduction to theoretical linguistics. Cambridge: Cambridge University Press.

Moravcsik, Edith A. (1978): "Reduplicative constructions". In: Greenberg, Joseph H. (ed.): Universals of human language. Word structure. Stanford, Stanford University Press: 297334.

Newmeyer, Frederick J. (1992): Iconicity and generative grammar. Language 68: 756-796.

Rooryck, Johan (1992): "On the distinction between raising and control". In: Hirschbühler, Paul/Koerner, Ernst F. K. (eds.): Romance languages and modern linguistic theory. Papers from the $20^{\text {th }}$ linguistic symposium on Romance languages. Amsterdam, John Benjamins: 225-250. (= Current issues in linguistic theory 91).

Sapir, Edward (1921): Language. An introduction to the study of speech. New York: Harcourt, Brace and World.

Saussure, Ferdinand de (1916): Course de linguistique générale. Paris: Payot.

Sedley, David (2003): Plato's Cratylus. Cambridge: Cambridge University Press.

Shibatani, Masayoshi (1975): A linguistic study of causative constructions. Bloomington: Indiana University Press. 
Shibatani, Masayoshi (1976): "The grammar of causative constructions. A conspectus". In: Shibatani, Masayoshi (ed.): The grammar of causative constructions. New York, Academic Press: 5-41. (= Syntax and Semantics 6).

Shibatani, Masayoshi (2001) (ed.): The grammar of causation and interpersonal manipulation. Amsterdam/Philadelphia: John Benjamins.

Shibatani, Masayoshi/Pardeshi, Prashant (2001): "The causative continuum". In: Shibatani, Masayoshi (ed.): The grammar of causation and interpersonal manipulation. Amsterdam/Philadelphia, John Benjamins: 85-126.

Song, Jae J. (1996): Causatives and causation. A universal-typological perspective. London/New York: Addison Wesley Longman.

Spencer, Andrew (1991): Morphological theory. An introduction to word structure in generative grammar. Cambridge: Basil Blackwell.

Talmy, Leonard (2003): Toward a cognitive semantics. Cambridge, MA: The MIT Press.

Van Langendonck, Willy (1995): "Categories of word order iconicity". In: Landsberg, Marge E. (ed.): Syntactic iconicity and linguistic freezes: The human dimension. Berlin, Mouton de Gruyter: 79-90.

Velázquez-Castillo, Maura (2001): "Guaraní causative constructions". In: Shibatani, Masayoshi (ed.): The grammar of causation and interpersonal manipulation. Amsterdam/Philadelphia, John Benjamins: 507-534.

Wilcox, Sherman (2004): "Conceptual spaces and embodied actions. Cognitive iconicity and signed languages". Cognitive Linguistics, 15/2: 119-147. 


\section{Appendix - Guide to Persian transcription symbols}

\begin{tabular}{|c|c|c|c|c|c|}
\hline Symbol & Example & Symbol & Example & Symbol & Example \\
\hline aa & arm & $\mathrm{p}$ & pen & $\mathrm{t}$ & tea \\
\hline o & or & $\mathrm{S}$ & so & $\mathrm{j}$ & joke \\
\hline $\mathrm{u}$ & too & $\mathrm{ch}$ & change & $\mathrm{h}$ & house \\
\hline $\mathrm{a}$ & hat & $\mathrm{x}$ & $\underline{\text { xub }}$ & $d$ & door \\
\hline e & ten & Z & zooo & $\mathrm{r}$ & red \\
\hline $\mathrm{i}$ & sheep & $\mathrm{zh}$ & vision & sh & shoe \\
\hline$q$ & Qom & $\mathrm{n}$ & noon & $\mathrm{f}$ & $\overline{\text { foot }}$ \\
\hline $\mathrm{k}$ & kill & $\mathrm{y}$ & yard & $\mathrm{g}$ & good \\
\hline 1 & land & ? & PalPaan & $\mathrm{m}$ & moon \\
\hline $\mathrm{V}$ & voice & $\mathrm{b}$ & bad & & \\
\hline
\end{tabular}

The / $/$ symbol represents glottal stop, and is used at the beginning of Persian syllables followed by a vowel.

The /q/ (i. e., a radical stop) and /x/ (i. e., a radical fricative) represent Persian-specific consonants.

The Persian sporadic feature tashdid is represented by the repetition of the phoneme that receives it. 